\section{Is There a Right Time to Know? The Right Not to Know and Genetic Testing in Children}

\author{
Pascal Borry, Mahsa Shabani, \\ and Heidi Carmen Howard
}

\section{Introduction}

In the last few decades, great progress has been made in both genetic and genomic research. The development of the Human Genome Project has increased our knowledge of the genetic basis of diseases and has given a tremendous momentum to the development of new technologies that make widespread genetic testing possible and has increased the availability of previously inaccessible genetic information. Two examples of this exponential evolution are the increasing implementation of next-generation sequencing technologies in the clinical context and the expanding commercial offer of genetic tests directly-to-consumers.

Firstly, the rapid development of next generation sequencing technologies (i.e., high-throughput and massively parallel DNA sequencing technologies) has substantially reduced both the cost and the time required to sequence an entire human genome. These technologies are increasingly being used in the clinical setting with the goal of diagnosing conditions of presumed genetic origin that cannot be explained by targeted sequencing approaches. By exploring the whole genome of individuals, the likelihood of detecting genetic variants with reproductive or clinical implications, as well as genetic variants with unknown significance, becomes an increasing reality. ${ }^{1}$ Cases are being reported about the implementation of next generation sequencing technologies in adults ${ }^{2}$ as well as in children. ${ }^{3} \mathrm{~A}$ recent publication also showed the potential benefit of using exome sequencing or whole genome sequencing (WGS) in a symptomatic newborn, allowing in a short time, the differential diagnosis and faster progression to genetic and prognostic counseling. ${ }^{4}$ Looking at the entire genome will reveal "incidental" findings, which are unrelated to the clinical request, as well as a number of genetic variants for which the meaning remains unclear. This new situa-

Pascal Borry, Ph.D., is Assistant Professor of Bioethics at the Centre for Biomedical Ethics and Law (University of Leuven, Belgium). He is the Programme Coordinator of the Erasmus Mundus Master of Bioethics. Within the European Society of Human Genetics, he is a member of the Professional and Public Policy Committee (2008-2014) and an elected member of the board (2012-2017). Pascal Borry is involved in various national and international research projects, such as Eurogentest, Genebanc, Engage, Eucellex and Pacita. Mahsa Shabani, LL.M., is a Ph.D. researcher at the Center for Biomedical Ethics and Law (University of Leuven, Belgium). In 2011 she graduated from the Erasmus Mundus Master of Bioethics program and subsequently has been involved in a variety of research activities in the area of ethical, legal, and social aspects of genomics. Heidi Carmen Howard, Ph.D., is Assistant Professor at Radboud University Medical Centre in Nijmegen, the Netherlands. She is a member of the Professional and Public Policy Committee of the European Society of Human Genetics. 
tion challenges and intensifies debates about clinical utility, policies regarding return of results, and procedures with regard to informed consent. ${ }^{5}$

Secondly, more and more companies are advertising and/or selling direct-to-consumer (DTC) genetic tests. The types of DTC genetic tests available are broad, from preconceptional carrier tests for single-gene disorders, such as cystic fibrosis (predicting a high risk of having affected offspring if both partners are carriers) to genetic association tests for predisposition to complex, multifactorial diseases, such as depression and degree prevents, defers or alleviates the outbreak of disease or the consequences of the outbreak of disease."11 The rationale behind this position is that, unless genetic testing earlier in life is in the best interest of the minor, testing in minors "should be delayed until the person is old enough to make an informed choice." ${ }^{2}$ For minors it is argued that in the provision of genetic testing, their "right not to know" should be respected as much as possible. Testing a minor early in life eliminates the possibility for the minor to make use of his or her "right not to know."

\section{A particular concern is how the volume of novel information will affect the processing of genetic and genomic information from minors. Although testing minors when there is a direct health benefit for the child is relatively uncontroversial, concerns remain about the ethical responsibility of parents and health care professionals with respect to the release of information that is of no immediate use for a child's health.}

cardiovascular disease. ${ }^{6}$ In addition to providing test results DTC, some commercial companies also made recommendations regarding lifestyle changes on the basis of these results, such as changes in diet or use of nutritional supplements. ${ }^{7}$ Various critiques have been raised regarding DTC genetic testing, including the lack of clinical validity and clinical utility of the tests being sold; the lack of quality control of the tests and laboratories involved in test provision as well as the qualifications of the personnel involved; the (misleading or unclear) advertisement of genetic tests; the inadequate process of informed consent and genetic counseling; the inappropriate genetic testing of children; the lack of individualized medical supervision; the downstream impact on the health care system; and the potential infringement of research ethics guidelines. ${ }^{8}$

A particular concern in both situations is how the volume of novel information will affect the processing of genetic and genomic information from minors. Although testing minors when there is a direct health benefit for the child is relatively uncontroversial, concerns remain about the ethical responsibility of parents and health care professionals with respect to the release of information that is of no immediate use for a child's health. At this moment, clinical-ethical guidelines $^{9}$ argue that testing in minors is only recommended when "established, effective, and important medical treatment" 10 is available, or when testing "provides scope for treatment which to any essential
Various legislative systems have recognized the "right not to know" as a patient's right. Generally speaking, individuals have a right to expressly instruct health care professionals against disclosure of specific personal health information. This gives individuals the ability to control their own personal health information and practice their "right not to know." Nevertheless, most statutes allow information to be disclosed to prevent or reduce a risk of serious bodily harm to an identifiable person. The "right not to know" has been predominantly recognized in the processing of genetic information, respecting individuals' wish not to be informed about specific genetic information or not to be tested for a specific genetic condition. For example, this right was integrated in article $5 \mathrm{c}$ of the UNESCO Universal Declaration on the Human Genome and Human Rights: "the right of every individual to decide whether or not to be informed of the results of genetic examination and the resulting consequences should be respected."13 Article 10 (2) of the European Convention on Human Rights and Biomedicine also states that "Everyone is entitled to know any information collected about his or her health. However, the wishes of individuals not to be so informed shall be observed."

The objective of this article is to discuss the "right not to know" with regard to the increasing availability of genomic testing and consequently the increased possibility of having genomic information processed from minors. The first part of the article discusses two 
theoretical underpinnings of the "right not to know": the respect for future autonomy and the respect for privacy. It is followed by a discussion of the concept of best interests in relation to the "right not to know." The second part of the article analyzes the reasons why various direct-to-consumer companies process samples from minors. The last part of the articles analyses various issues that are at stake when considering genetic testing for common complex disorders in a pediatric population.

\section{The Right Not to Know and the Respect for Future Autonomy}

The respect for autonomy is often advanced as the theoretical basis for the "right not to know."14 The choice of not knowing certain information is considered as an expression of the own choices of an individual, which could be framed as a right to informational selfdetermination. In this case it is not the physician who decides what information to provide to the patient, but it is the patient who fully takes on the responsibility and the action of deciding which information he or she wants or does not want to receive.

The right not to know has also been advanced as a relevant right for minors. Although a child may not have the necessary competence and maturity to take autonomous decisions now, there are important reasons to keep certain future options open and not limit them by current decisions that do not need to be made now. This was defined by Joel Feinberg as a "right to an open future."15 Feinberg called these rights "rightsin-trust": rights that have to be preserved for the child until he is an adult.

The concept of the "right to an open future" and the "right not to know" has also been applied in the context of genetic testing in children. Regarding the specific case of predictive genetic testing for Huntington's disease, Dena Davis comments:

The notion of the child's right to an open future can help in confronting the question of whether to test children for adult-onset genetic diseases, for example Huntington disease. It is well known that the vast majority of adults at risk for Huntington disease choose not to be tested. However, it is not uncommon for parents to request that their children be tested; their goals may be to set their minds at rest, to plan for the future, and so on. On one account, parental authority to make medical decisions suggests that clinicians should accede to these requests (after proper counseling about possible risks). A better account, in my opinion, protects the child's right to an open future by preserving into adulthood his own choice to decide whether his life is better lived with that knowledge or without. ${ }^{16}$

The future autonomy of the child may outweigh the autonomy of parents in this context and might justify the withholding of information from parents. In this case information appears as belonging to the informational self-determination of the child as future adult. Therefore, the future child's personal consent as an adult takes precedence over the potential actual parental choice.

This rationale was recently confirmed by the British Society for Human Genetics guidelines on "Genetic Testing in Children" (in the context of performing predictive and pre-symptomatic testing on asymptomatic minors) by recommending that "in such circumstances testing should normally be delayed until the young person can decide for him/herself when, or whether, to be tested."17

\section{The Right Not to Know and the Respect for Privacy}

Graeme Laurie highlighted that in addition to autonomy as an underlying theoretical underpinning of the right not to know, another basis is a special type of spatial privacy, in which an individual's self is being protected. "Spatial privacy (...) ensures that the individual herself is in a state of non-access. An obvious example of this is physical separateness from others - physical spatial privacy is invaded when one's physical sphere is invaded - if, for example, we are not permitted to be alone. However, spatial privacy also encompasses separateness of the individual's psyche...."18

In relation to minors, the spatial privacy of the child requires that one refrains from processing any sensitive or private information which is not of immediate use to the child. This is not only based on the fact that certain information might create potential harm for the child. It may also disrespect potential future wishes of that child and undermine the previously described respect for autonomy. Secondly, it might also compromise the spatial privacy interests.

Control of information about ourselves must be an essential part of any concept of ourselves as autonomous persons, but "control" should not be limited merely to control of who has access to that information. It should also include the facility not to accept the information ab initio. A concept of "control" which is wide enough to encompass this notion permits us to retain a private sphere that is truly our own. Furthermore, it allows us to maintain that unsolicited revelations of personal information is an invasion of that 
sphere, even when such revelations about ourselves are made to ourselves. ${ }^{19}$

\section{The Right Not to Know and the Best Interests of the Child}

When considering health care decisions involving children, the concept of "best interests" takes a central position. In particular in relation to incompetent or immature minors, parents have the authority to make decisions on behalf of their children, which should be in their "best interests." Allen Buchanan and Dan Brock defined this as "acting to promote the good of the individual to the maximum extent." ${ }^{20}$ This concept of the child. In this situation, the test is either permissible or even obligatory. ${ }^{26}$ What is in the best interest of a minor, however, is not always crystal-clear.

\section{The Right Not to Know and Direct-to- Consumer Genetic Testing}

An illustrative example of debates around the interpretation of what are the best interests of minors can be gleaned in the discussions surrounding DTC genetic testing. ${ }^{27}$ In 2008, an analysis of DTC companies' websites, including their consent forms, terms of services and privacy policy statements indicated that various companies allow genetic testing in minors

The importance to act in the best interests of minors automatically points to the limitations of the right not to know. Like most rights, the right not to know is not an absolute one. When the disclosure of information is necessary in order to avoid a serious harm to the child or in order to initiate preventive measures or therapy, this provides a justification for performing a certain (genetic) test. There is broad consensus regarding medical benefit, whereby a genetic test is likely to provide useful information for the medical management of the child, the test is either permissible or even obligatory. What is in the best interest of a minor, however, is not always crystal-clear.

has been frequently used in the academic literature in relation to various ethical discussion related to healthcare decisions involving children. ${ }^{21}$ Moreover, various international documents, such as the Charter of the Fundamental Rights of the European Union ${ }^{22}$; the Universal Declaration on the Human Genome and Human Rights ${ }^{23}$; or the Convention on the Rights of the Child ${ }^{24}$ advance that the "best interests" concept should be a standard in decisions involving children. Article 3.1 of the latter document stipulates that "in all actions concerning children, whether undertaken by public or private social welfare institutions, courts of law, administrative authorities or legislative bodies, the best interest of the child shall be a primary consideration." ${ }^{25}$

The importance to act in the best interests of minors automatically points to the limitations of the right not to know. Like most rights, the right not to know is not an absolute one. When the disclosure of information is necessary in order to avoid a serious harm to the child or in order to initiate preventive measures or therapy, this provides a justification for performing a certain (genetic) test. There is a broad consensus regarding medical benefit, whereby a genetic test is likely to provide useful information for the medical management upon parental request and/or authorization. ${ }^{28} \mathrm{~A}$ questionnaire study (collecting information directly from the companies) aimed at obtaining information regarding the policies on genetic testing in children also indicated that not only would some of these companies perform genetic testing in minors under parental or legal guardian requests, but that a large majority of the responding companies had already received requests from parents or legal guardians to test minors. ${ }^{29}$

Different reasons might explain why various DTC companies accept to process samples from minors. Firstly, limiting the pool of individuals from which tests can be processed, might also limit the total number of tests processed. It is financially more interesting for a DTC company when entire families can buy their services at once. Therefore, there are various examples of companies that provide price reductions on orders including more than one individual. For example, easyDNA provides a discount when you order tests for more than one person at a time..$^{30}$

Secondly, various companies underline that their services provide individuals with information that gives them insights into potential future health risks and enables them to initiate behavioral and lifestyle 
changes. Therefore, the companies offering these services claim that the information provided might not only be helpful for adults, but also for children. In response to the previously mentioned questionnaire, various companies stated that genetic testing in children can be useful. ${ }^{31} \mathrm{~A}$ company stated that "[n]onmedical genetic information can help parents better understand their child's innate strengths and weaknesses, and help in successfully raising the child" (Company U). Another company stated that "[o]ur genetic tests, which are both predictive and clinical in nature, can be useful tools in the diagnosis, prevention, and treatment of a wide range of health conditions. The benefits of this function are not limited to individuals over the age of 18 , and therefore we believe genomic information is something over which individuals should have control. Interestingly, this is contradictory to their explicit position about why consumers should be able to get tested DTC. Furthermore, by testing minors they send a message that they do not consider it to be disrespectful towards the autonomy of a future adult, nor that it compromises the above mentioned idea of spatial privacy - both notions which theoretically underpin the notion of the right not to know.

The Right Not to Know and Genetic Testing for Common Complex Disorders in Children The fact that various DTC genetic testing companies process samples from minors challenges some of the

\section{As the "right not to know" is meant to provide individuals the possibility of an open future, based on the underlying values of respect for autonomy and privacy, an important question is to what extent this principle should apply to genetic testing for common complex disorders. As described earlier, the provision of medical benefit (in terms of therapeutic or preventive benefit) has been advanced as a legitimate reason to test minors in clinical ethical guidelines. Most DTC companies offer predictive genomic testing that provides risk information for common complex disorders. A major discussion revolves around the value of this type of information.}

that - with parental consent and the guidance and interpretation of a qualified physician - our tests may be performed on minors as well as on adults" (Company $S$ ).

Thirdly, the companies that allow genetic testing of minors underline that decisions about genetic testing of minors belong to the realm of parental discretion. In contrast to the view that predictive genetic testing of asymptomatic minors should be limited to considerations of best interests and an open future, the advocated position is that parents are entitled to make decisions with regard to genetic testing of their children. In a previous study, it has been reported that various DTC genetic testing companies advance in their terms of service that the parent or guardian assumes full responsibility for ensuring that the information that he/she provides about his or her child is kept secure and that the information submitted is accurate. ${ }^{32}$ This suggests that the decision about this type of testing is similar to other types of health care decisions that parents typically make.

In conclusion, by testing minors, these DTC genetic testing companies implicitly discard the notion that basic principles that have been accepted in clinical practice with regard to the predictive genetic testing of minors and which were endorsed by various medical and genetic associations in the context of monogenic disorders. ${ }^{33}$ However, these guidelines were elaborated with predictive genetic testing or carrier testing of monogenetic conditions in mind. In this context, ethical reflection ${ }^{34}$ has always been concerned with the careful transfer of information about genetic tests and test results, the confidentiality of genetic information, the voluntariness of requesting a genetic test, the responsibility towards blood relatives, and the (potential) psychosocial impact of a test on the applicant. ${ }^{35}$ An even more cautious approach has been envisaged when considering such testing in children and adolescents. As the "right not to know" is meant to provide individuals the possibility of an open future, based on the underlying values of respect for autonomy and privacy, an important question is to what extent this principle should apply to genetic testing for common complex disorders. As described earlier, the provision of medical benefit (in terms of therapeutic or preventive benefit) has been advanced as a legitimate rea- 
son to test minors in clinical ethical guidelines. Most DTC companies offer predictive genomic testing that provides risk information for common complex disorders. A major discussion revolves around the value of this type of information. Beth Tarini et al. ${ }^{36}$ defend that "predictive genomic testing may be able to identify an individual's risk for developing common treatable, and possibly preventable disorders which can promote environmental modifications, such as lifestyle and health behavior change." ${ }^{37}$ The underlying vision advanced here is that through the possibility of offering this type of testing, individuals will be able to change their lifestyle and behavior, and consequently reduce their chances of developing certain conditions. As various risk factors (e.g., smoking, diet, or physical activity) for common disorders are initiated in childhood or before adulthood, some might argue that earlier lifestyle and behavior changes will improve overall health. ${ }^{38}$

The confirmed presence of medical benefits would provide a legitimate justification to perform this type of predictive testing in minors. Most of the genetic tests for common complex disorders, however, have a low predictive value. "Most genetic variants may only alter the disease susceptibility risk by a factor of 1.1-1.6, and usually a large number of genetic variants will have a bearing on the risk, of which only a minority will be known or included in test panels. In most cases of polymorphic variants, the predictive value would be too small for any intervention to be appropriate, and it is disputed whether a combination of risk variants could confer a sufficiently high relative risk to support the recommendation of testing or screening in case risk-reducing interventions become available." ${ }^{39}$ Common complex disorders are caused by an interplay of genetic and environmental factors. Therefore, the predictive ability of a model using those genetic risk factors is usually limited because of the relatively few number of low-risk variants that have been discovered so far ${ }^{40}$ and by the fact that common complex disorders are only partially heritable. ${ }^{41}$ Tarini at al. ${ }^{42}$ provide the example that it might be possible to test obese children to see whether they have an elevated genetic risk of developing type 2 diabetes in addition to their risk based on the fact that they are obese. However, the utility of doing this is questionable as various studies showed that genetic risk scores have lower discriminative accuracy than clinical risk factors. ${ }^{43}$ This formed the basis of a European guideline that concluded that "despite the encouraging progress in our understanding of the genetic basis of T2DM, it is too early to use genetic information as a tool for targeting preventive efforts." ${ }^{44}$ As a conclusion, if the predictive ability is limited and preventive options (including lifestyle changes) exist without using genomic information of debated utility, it is questionable whether the test result would lead to any different decision or additional benefit that exists without using the genomic information. DTC companies also justify their genetic testing services by referring to the fact that they may motivate individuals to adopt healthier lifestyles and thus lead to behavior changes. However, the limited research with common genetic variants has shown that there is little impact on behavior change. ${ }^{45}$ Considering that the genetic testing of minors does not provide a clear prospect of medical benefit, a question remains: does the absence of harm to minors justify the undertaking of genetic tests for common complex disorders?

Based on anticipated potential harms, existing professional recommendations have always advanced a cautionary position towards predictive genetic testing. As we can read, for example, in the Working Party of the Clinical Genetics Society: "The potential harms caused by childhood genetic testing might include damage to the child's self-esteem, distortion of the family's perceptions of the child, loss of future adult autonomy and confidentiality, discrimination against the child in education, employment or insurance, and adverse effects on the child's capacity to form future relationships." ${ }^{\prime 6}$ This position has often been criticized because of the fact that these harms were more speculative and not based on actual evidence. ${ }^{47}$ In particular, related to susceptibility testing for common disorders, there is also debate over the possibility that such testing might lead to fatalistic behavior, distress, or other psychological, relational, or societal effects. The current available evidence does not show that the information received from DTC companies causes significant individual harm, such as increased anxiety or worry ${ }^{48}$ Based on the absence of proof of harms, some have argued that the rationale not to accept genomic testing is exaggerated. ${ }^{49}$

Nevertheless, focusing the debate on the acceptability of this type of testing due to the absence of harms to individuals undergoing genomic testing distorts the focus of the debate from other relevant issues. Firstly, the amount of empirical data is still limited. A systematic review of the literature concluded that "there is insufficient evidence to inform a nuanced undertstanding of how children respond to genetic testing. This suggests a strong need for further research that uses rigorous approaches to address children's emotional states, self-perception, and social wellbeing."50 In this regard, Patenaude also concluded that "the vulnerabilities of children to genetic information are not yet well understood." ${ }^{11}$ Moreover, it is also a ques- 
tion whether this issue could be resolved by evidence only. Decisions about testing minors might be more informed by values and norms than by evidence.

Secondly, harms might not always be situated at the individual level, but might be situated at the public health level. The premature introduction of genetic tests might lead to increased recourse to health care professionals within the public health care system, including primary care physicians, clinical geneticists, or other specialists. If such a referral is based on an inappropriate test, it might lead to false negatives and false positives, misinterpretations, inappropriate follow-up testing, and unnecessary lifestyle changes or preventive actions. Creating this type of downstream impact might not only negatively affect the health care system, but also patients' health. ${ }^{52}$ That being said, in the near future more and more genetic tests for common complex disorders might become available. Their introduction should be dependent on the condition that sufficient information is available on the clinical validity and utility of those tests and that by doing the test additional relevant information can be gained about the diagnosis, prognosis, preventive actions, or disease management.

Thirdly, testing minors denies them the opportunity to make these decisions for themselves later on in life. On the one hand, we see that adults might have various reasons to decide to buy a DTC genetic test including motivations related to health, curiosity or fascination, genealogy, the willingness to contribute to research, and for recreational purposes. ${ }^{53} \mathrm{On}$ the other hand, we also see that many adults decide not to buy these services. They might not be interested to know if they have an increased risk for specific disorders that run in the family; they might not want to know what their risk profiles are for various conditions, or whether they are carrying mutations for autosomal recessive or X-linked conditions. They might not be interested in contributing to research. Although some might argue that everyone has, to some extent, an ethical duty to know this kind of information, in the case of adults, we definitely accept the right not to know this type of information. Also DTC genetic testing companies do, in a way, accept the notion of spatial privacy by, for example, stating that "the only people who should be able to see your genetic information are you and those with whom you choose to share it." ${ }^{44}$ Testing minors for common complex disorders ignores the fact that minors, once they become adults, may not have the same ideas about the desirability of accessing this type of information. This is of course true for many decisions parents make for their children. Given the existing differences between adults about whether or not to undergo such testing, and whether or not to share genomic information, there are still good reasons not to abandon the "right not to know."

\section{Conclusion}

Traditionally, predictive genetic testing in minors is surrounded by values that emphasize the best interests of the minors, voluntary choice, autonomous decision-making, informed decision-making, respect for privacy, and non-directiveness. If the medical benefits are absent or uncertain, then the justification for testing is less compelling. A crucial principle in this regard is the right not to know, which has been used to attribute to minors an informational self-determination with regard to genetic information. With the advent of DTC genetic testing companies, much debate has taken place about the legitimacy of this principle in this context. Several studies also suggest that various parents might have an interest in predictive genomic testing in their children..$^{55}$ As expressed by one of the parents that had their children tested: "at a more practical level, I want to give my kids as much information as possible about the cocktail they are inheriting from my husband and me, so they can better manage their health." ${ }^{56}$

The debate about the acceptability of testing minors within the realm of DTC genetic testing is complex. It is clear that predictive testing for low penetrance variants does not cause the same ethical, psychological, or emotional concerns as predictive testing for highly penetrant monogenic conditions. However, given the concerns about the limited clinical validity and utility of many tests, many concerns persist about the desirability of such testing. These include concerns about the limited knowledge of the impact of such testing on adults and minors; the potential downstream impact on the health care system; and the fact that various individuals might make different value-laden choices about the desirability of such testing. While it is hard to prevent parents in a DTC context from submitting samples from minors to genetic testing companies, this debate brings to the agenda a much broader debate concerning the parental rights to their children's genomic information. While we focused here mainly on genetic testing for common complex disorders, the debate expands to other types of genomic information. Moreover, the implementation of next generation sequencing technologies will increasingly raise the question of what kind of information should be returned to the families that undergo such testing. Current opinions range from returning no incidental medical information to returning large amounts of information (including personal and familial genetic risk factors for disease), to returning all genetic data 
so that the sequencing data remains available in the future. ${ }^{57}$ The actual character of this debate is exemplified within the recent recommendations of the American College of Medical Genetics and Genomics. ${ }^{58}$ In their document on incidental findings in clinical exome and genome sequencing, they advanced that "ethical concerns about providing children with genetic risk information about adult-onset diseases were outweighed by the potential benefit to the future health of the child and the child's parent of discovering an incidental findings where intervention might be possible." This document clearly puts limitations on the child's right to know and considers that the benefits of providing parents the opportunity to discover life-threatening risk information supersede the right not to know of the child. The debate on the validity and the limitations of the "right not to know" will certainly continue to remain on the agenda of the debates on genetic testing in minors, as well as in debates over the best interests of children, parental responsibility and discretion, and duties of health care professionals.

\section{Acknowledgements}

Part of this work was kindly supported through the Research Fund Flanders and the FP7-project EUcelLEX (grant agreement no. 601806).

\section{References}

1. J. J. Johnston, W. S. Rubinstein, and F. M. Facio et al., "Secondary Variants in Individuals Undergoing Exome Sequencing: Screening of 572 Individuals Identifies High-Penetrance Mutations in Cancer-Susceptibility Genes," American Journal of Human Genetics 91, no. 1 (2012): 97-108; C. Netzer, C. Klein, J. Kohlhase, and C. Kubisch, "New Challenges for Informed Consent through Whole Genome Array Testing," Journal of Medical Genetics 46, no. 7 (2009): 495-496; H. Ostrer, "Changing the Game with Whole Exome Sequencing," Clinical Genetics 80, no. 2 (2011): 101-103.

2. Id. (Johnston et al.); E. A. Ashley, A. J. Butte, and M. T. Wheeler et al., "Clinical Assessment Incorporating a Personal Genome," The Lancet 375, no. 9725 (2010): 1525-1535.

3. A. N. Mayer, D. P. Dimmock, and M. J. Arca et al., "A Timely Arrival for Genomic Medicine," Genetics in Medicine 13, no. 3 (2011): 195-196; B. D. Solomon, D. W. Hadley, and D. E. PinedaAlvarez et al., "Incidental Medical Information in Whole-Exome Sequencing," Pediatrics 129, no. 6 (2012): e1605-e1611; E. A. Worthey, A. N. Mayer, and G. D. Syverson et al., "Making a Definitive Diagnosis: Successful Clinical Application of Whole Exome Sequencing in a Child with Intractable Inflammatory Bowel Disease," Genetics in Medicine 13, no. 3 (2011): 255-262.

4. C. J. Saunders, N. A. Miller, and S. E. Soden et al., "Rapid Whole-Genome Sequencing for Genetic Disease Diagnosis in Neonatal Intensive Care Units," Science Translational Medicine 4, no. 154 (2012): 154ra135.

5. R. Hastings, G. de Wert, and B. Fowler et al., "The Changing Landscape of Genetic Testing and Its Impact on Clinical and Laboratory Services and Research in Europe," European Journal of Human Genetics 20, no. 9 (2012): 911-916; L. G. Biesecker, W. Burke, and I. Kohane et al., "Next-Generation Sequencing in the Clinic: Are We Ready?" Nature Revieres Genetics 13, no. 11 (2012): 818-824.
6. H. C. Howard and P. Borry, "Personal Genome Testing: Do You Know What You Are Buying?" American Journal of Bioethics 9, nos. 6-7 (2009): 11-13.

7. H. C. Howard and P. Borry, "Direct-to-Consumer Genetic Testing: More Questions Than Benefits?" Personalised Medicine 5, no. 4 (2008): 317-320.

8. European Society of Human Genetics, "Statement of the ESHG on Direct-to-Consumer Genetic Testing for HealthRelated Purposes," European Journal of Human Genetics 18, no. 12 (2010): 1271-1273; H. C. Howard, B. M. Knoppers, and P. Borry, "Blurring Lines: The Research Activities of Direct-toConsumer Genetic Testing Companies Raise Questions about Consumers as Research Subjects," EMBO Reports 11, no. 8 (2010): 579-582.

9. P. Borry, L. Stultiens, and H. Nys et al., "Presymptomatic and Predictive Genetic Testing in Minors: A Systematic Review of Guidelines and Position Papers," Clinical Genetics 70, no. 5 (2006): 374-381.

10. German Society of Human Genetics, Statement on Genetic Diagnosis in Children and Adolescents, 1995, available at <http://www.gfhev.de/en/gfh/> (last visited January 20, 2014).

11. Danish Council of Ethics, Genetic Investigation of Healthy Subjects - Report on Presymptomatic Gene Diagnosis, 2001, available at <http://www.etiskraad.dk/sw293.asp> (last visited January 20, 2014).

12. P. Borry, G. Evers-Kiebooms, and M. C. Cornel et al., "Genetic Testing in Asymptomatic Minors: Recommendations of the European Society of Human Genetics Recommendations of the European Society of Human Genetics," European Journal of Human Genetics 17, no. 6 (2009a): 720-721.

13. Unesco, Universal Declaration on the Human Genome and Human Rights, 1997, Paris.

14. R. Andorno, "The Right Not to Know: An Autonomy Based Approach," Journal of Medical Ethics 30, no. 5 (2004): 435-439.

15. J. Feinberg, "The Child's Right to an Open Future," W. Aiken and H. LaFolette, eds., In Whose Child? Children's Rights, Parental Authority, and State Power (Totowa: Adams \& Co, 1980): at 124-153.

16. D. D. Davis, "Genetic Dilemmas and the Child's Right to an Open Future," Hastings Center Report 27, no. 2 (1997): 7-15.

17. British Society for Human Genetics, "Genetic Testing of Children: Report of a Working Party of the British Society for Human Genetics," 2010, available at <http:// www.publichealth.ox.ac.uk/ethox/ethox-photo-archive/ GTOC 2010 BSHG.pdf> (last visisted January 28, 2014). G. T. Laurie, "In Defence of Ignorance: Genetic Information and the Right Not to Know," European Journal of Health Law 6, no. 2 (1999): 119-132.

18. Id.

19. A. E. Buchanan and D. W. Brock, eds., Deciding for Others (Cambridge: University Press, 1989).

20. A. Dawson, "The Determination of the Best Interests in Relation to Childhood Immunisation," Bioethics 19, no. 1 (2005): 72-89; R. S. Downie and F. Randall, "Parenting and the Best Interests of Minors," Journal of Medicine $\&$ Philosopy 22, no. 3 (1997): 219-231; L. F. Ross, "Genetic testing of Adolescents: Is It in Their Best Interest?" Archives of Pediatrics and Adolescent Medicine 154, no. 8 (2000): 850-852; K. Spence, " The Best Interest Principle as a Standard for Decision Making in the Care of Neonates," Journal of Advanced Nursing 31, no. 6 (2000): 1286-1292; J. M. Trau and J. J. McCartney, "In the Best Interest of the Patient: Applying This Standard to Healthcare Decision Making Must Be Done in a Community Context," Health Progress 74, no. 3 (1993): 50-56.

21. European Parliament, Charter of Fundamental Rights of the European Union, 2000, available at <http://www.europarl. europa.eu/charter/pdf/text_en.pdf> (last visited January 21, 2014).

22. See Unesco, supra note 13. 
23. United Nations, Convention on the Rights of the Child, 1989, available at <http://www.unhchr.ch/html/menu3/b/k2crc. htm>.

24. $I d$.

25. P. Borry, T. Goffin, H. Nys, and K. Dierickx, "Predictive Genetic Testing in Minors for Adult-Onset Genetic Diseases," Mount Sinai Journal of Medicine: A Journal of Translational and Personalized Medicine 75, no. 3 (2008): 287-296.

26. P. Borry, H. C. Howard, K. Sénécal, and D. Avard, "Directto-Consumer Genome Scanning Services: Also for Children?" Nature Revieres Genetics 10, no. 1 (2009c): 8.

27. P. Borry, H. C. Howard, K. Sénécal, and D. Avard, "HealthRelated Direct-to-Consumer Genetic Testing: A Review of Companies' Policies with Regard to Genetic Testing in Minors," Famillial Cancer 9, no. 1 (2010): 51-59.

28. H. C. Howard, D. Avard, and P. Borry, "Are the Kids Really All Right? Direct-to-Consumer Genetic Testing in Children: Are Company Policies Clashing with Professional Norms?" European Journal of Human Genetics 19, no. 11 (2011): 1122-1126.

29. Easy-DNA.com genetic testing services, available through <https://payments.easydna.net/products/index.php?location id=1\&product_category=10> (last visited January 21, 2014)

30. See Howard et al., supra note 29

31. See Borry et al., supra note 28.

32. H. K. Tabor, J. Stock, and T. Brazg et al., "Informed Consent for Whole Genome Sequencing: A Qualitative Analysis of Participant Expectations and Perceptions of Risks, Benefits, and Harms," American Journal of Medical Genetics 158A, no. 6 (2012): 1310-1319.

33. B. B. Biesecker, "Future Directions in Genetic Counseling: Practical and Ethical Considerations," Kennedy Insitute of Ethics Journal 8, no. 2 (1998): 145-160; M. B. Mahowald, M. S. Verp, and R. R. Anderson, "Genetic Counseling: Clinical and Ethical Challenges," Annual Review of Genetics 32 (1998): 547-559.

34. D. Allan, "Ethical Boundaries in Genetic Testing," Canadian Medical Association Journal 154, no. 2 (1996): 241-244.

35. B. A. Tarini, K. P. Tercyak, and B. S. Wilfond, "Commentary: Children and Predictive Genomic Testing: Disease Prevention, Research Protection, and Our Future," Journal of Pediatric Psychology 36, no. 10 (2011): 1113-1121.

36. Id.

37. $I d$.

38. C. G. van El and M. C. Cornel, "Genetic Testing and Common Disorders in a Public Health Framework," European Journal of Human Genetics 19, no. 4 (2011): 377-381.

39. A. C. Janssens and C. M. van Duijn, "Genome-Based Prediction of Common Diseases: Advances and Prospects," Human Molecular Genetics 17, no. R2 (2008): R166-R173.

40. A. C. Janssens and C. M. van Duijn, "An Epidemiological Perspective on the Future of Direct-to-Consumer Personal Genome Testing," Investigative Genetics 1, no. 1 (2010): 1-5.

41. See Tarini et al., supra note 36.

42. R. Mihaescu, J. Meigs, E. Sijbrands, and A. C. Janssens, "Genetic Risk Profiling for Prediction of Type 2 Diabetes," PLoS Currents 3 (2011): RRN1208; R. Mihaescu, M. Van Zitteren, and M. van Hoek et al., "Improvement of Risk Predic- tion by Genomic Profiling: Reclassification Measures Versus the Area under the Receiver Operating Characteristic Curve," American Journal of Epidemiology 172, no. 3 (2010): 353-361.

43. B. Paulweber, P. Valensi, and J. Lindström et al., "A European Evidence-Based Guideline for the Prevention of Type 2 Diabetes," Hormone and Metabolic Research 42, no. S01 (2010): S3-S36.

44. C. M. McBride, L. M. Koehly, S. C. Sanderson, and K. A. Kaphingst, "The Behavioral Response to Personalized Genetic Information: Will Genetic Risk Profiles Motivate Individuals and Families to Choose More Healthful Behaviors?” Annual Review of Public Health 31 (2010): 89-103.

45. A. Clarke, "The Genetic Testing of Children: Working Party of the Clinical Genetics Society (UK)," Journal of Medical Genetics 31, no. 10 (1994): 785-797.

46. R. E. Dunca and M. B. Delatycki, "Predictive Genetic Testing in Young people for Adult-Onset Conditions: Where Is the Empirical Evidence?" Clinical Genetics 69, no. 1 (2006): 8-16.

47. K. M. James, C. T. Cowl, and J. C. Tilburt et al., "Impact of Direct-to-Consumer Predictive Genomic Testing on Risk Perception and Worry among Patients Receiving Routine Care in a Preventive Health Clinic," Mayo Clinic Proceedings 86, no. 10 (2011): 933-940

48. A. Nordgren, "Neither as Harmful as Feared by Critics Nor as Empowering as Promised by Providers: Risk Information Offered Direct to Consumer by Personal Genomics Companies," Journal of Community Genetics 5, no. 1 (2012): 59-68.

49. C. H. Wade, B. S. Wilfond, and C. M. McBride, "Effects of Genetic Risk Information on Children's Psychosocial Wellbeing: A Systematic Review of the Literature," Genetics in Medicine 12 , no. 6 (2010): 317-326.

50. A. F. Patenaude, "Commentary: Save the Children: Direct-toConsumer Testing of Children Is Premature, Even for Research," Journal of Pediatric Psychology 36, no. 10 (2010): 1122-1127.

51. European Academies Science Advisory Council, Direct-toConsumer Genetic Testing for Health-Related Purposes in the European Union, 2012, available at <http://www.easac.eu/ fileadmin/Reports/EASAC Genetic Testing_Web_complete. pdf> (last visited January 21, 2014); see European Society of Human Genetics, supra note 8.

52. Y. Su, H. C. Howard, and P. Borry, "Users' Motivations to Purchase Direct-to-Consumer Genome-Wide Testing: An Exploratory Study of Personal Stories," Journal of Community Genetics 2, no. 3 (2011): 135-146.

53. See Borry et al., supra note 27.

54. K. P. Tercyak, S. Hensley Alford, and K. M. Emmons et al., "Parents' Attitudes toward Pediatric Genetic Testing for Common Disease Risk," Pediatrics 127, no. 5 (2011): e1288-1295; see $\mathrm{Hu}$ et al., supra note 53.

55. 23andMe website, available at <https://www.23andme.com> (last visited January 21, 2014).

56. See Solomon et al., supra note 3.

57. R. C. Green, J. S. Berg, and W. W. Grody et al., "ACMG Recommendations for Reporting of Incidental Findings in Clinical Exome and Genome Sequencing," Genetics in Medicine 15, no. 7 (2013) 565-574. 